\title{
Spices and Herbs as a Source of Natural Antioxidants for Food
}

\author{
Dhartiben B. Kapadiya*, Bhumika K. Dabhi and Kishorkumar D. Aparnathi \\ Dairy Chemistry Department, SMC College of Dairy Science, Anand Agricultural University, \\ Anand- 388110, Gujarat, India \\ *Corresponding author
}

\begin{abstract}
A B S T R A C T
Keywords

Spices and Herbs,

Natural

Antioxidants.

Article Info

Accepted:

12 June 2016

Available Online:

10 July 2016

The oxidative reactions limit the shelf life of fresh and processed foodstuff and are a serious concern in the food industry. The free radical formations leading to the oxidation of biomolecules are implicated in several diseases. Many foods are becoming more susceptible to oxidative rancidity due to attempts to make foods healthier by increasing polyunsaturated fatty acids and more sustainable by introducing light weight oxygen-permeable and light penetrating packaging. The use of synthetic antioxidants such as butylated hydroxytoluene (BHT) and butylated hydroxyanisole (BHA) have been used widely for many years to retard lipid oxidation, but current concern about their safety, together with increasing consumer preference for natural products, has resulted in an increased demand for natural antioxidants. Due to natural antioxidant components, spices and herbs are great sources of antioxidants for food preservation. Therefore, use of spices and herbs present a better choice than synthetic antioxidants, which has become popular and is widely accepted by consumers.
\end{abstract}

\section{Introduction}

Lipid oxidation causes oxidative stress, resulting in the development of rancidity, unpleasant tastes and odors as well as changes in color and losses of nutritional value (Darughe et al., 2012). Oxidative rancidity is a major cause of food quality deterioration, leading to the formation of undesirable aroma and off-flavors, color degradation as well as unhealthy compounds (Frankel, 2012). Control of oxidation of fats/oils and lipid-containing products may be achieved by excluding the initiator and promoter elements during processing and storage.
Lipid oxidation problems may be prevented by the use of antioxidants. Synthetic antioxidants such as butylated hydroxytoluene (BHT) and butylated hydroxyanisole (BHA) have been used widely for many years to retard lipid oxidation, but current concern about their safety (Sati et al., 2011), together with increasing consumer preference for natural products, has resulted in an increased demand for natural antioxidants. Due to natural antioxidant components, spices and herbs are great sources of antioxidants for food preservation. Numerous herbs and 
spices have the potential to retard lipid oxidation during storage of foods which is usually mediated through their intrinsic antioxidant activity of their constituents. Recently, the use of natural antioxidants in the food industries has increased rapidly and consequently many related studies have been reported (Ibrahium et al., 2013).

The herbs and spices have been used for centuries to preserve food and to make it more palatable and flavorful (Shahidi, 2015). Herbs come from leaves of a plant whose stem above ground does not become woody. A food herb is generally defined as the leaf of a plant when used in cooking, but any other part of the plant, often dried, can be a spice. Spices include flowers (clove), bulbs (garlic, onion), fruits (cumin, red chilli, black pepper), stems (coriander), bark (cinnamon), roots (ginger), berries (peppercorns), aromatic seeds (cumin) and other plant parts (Brewer, 2011; Kaefer and Milner, 2008).

Spices and herbs can be classified into various groups based on flavor/taste, part of the plant where they came from. Spices and herbs are used as antioxidants in different forms (Essential oils, aqueous or methanolic extracts, resins, whole and oleoresins in food (Peter, 2001). The use of spices and herbs dates back to about $1550 \mathrm{BC}$ as recorded in the Ebers Papyrus, listing spices such as anise, mustard, saffron, cinnamon, and cassia.

The spice trade was in existence at least 3500 years ago, evidencing the long history of safe use of spices and herbs (Shahidi, 2015; Suhaj, 2006). The U.S. Food and Drug Administration (FDA) refers to natural ingredients as "ingredients extracted directly from plants or animal products as opposed to being produced synthetically (Carlsen et al., 2010; Suhaj, 2006).

\section{Antioxidative compounds}

The antioxidant activity of herbs and spices is most often due to phenolic acids (gallic, protocatechuic, caffeic, and rosmarinic acids) phenolic diterpenes (carnosol, carnosic acid, rosmanol, and rosmadial), flavonoids (quercetin, catechin, naringenin, kaempferol, epicatechin, gallate, epigallocatechin gallate and rutin), volatile oils (eugenol, carvacrol, thymol, menthol, safrole, 1,8-cineole, $\alpha$-terpineol, p-cymene, cinnamaldehyde, myristicin and piperine) and phenylpropanoids (thymol, eugenol, carvacrol, p-cymene) (Frankel, 2012; Brewer, 2011).

Some plant pigments (anthocyanin and anthocyanidin) also have an antioxidative activity. Coumarin (warfarins, suksdorfin and coriandrin) and alkaloids (piperin, colchincine, hydrastin and berberin) also gives the antioxidative effect (Kaefer and Milner, 2008; Carlsen et al., 2010).

\section{Mechanism of Action}

The oxidation of lipids proceeds through three different stages: initiation, propagation, and termination. Hydroperoxides and secondary oxidation products (aldehydes, ketones, acids, etc.) are responsible for the rancid aroma and offflavors in foods (Pokorny et al., 2001).

The different factors catalyses the lipid oxidation are the presence of oxygen and metal ions, heat, and light. To prevent, minimize, or slow down the rate of lipid oxidation, oxygen and metal catalysts must be removed or sequestered to render them unreactive. The food prone to oxidation must be stored at low temperatures and/or shielded from light. To prevent the oxidation, antioxidant acts effective way by acting at different stages of lipid oxidation 
such as initiation, propagation, and termination (Shahidi, 2015).

Phenolic compounds are bioactive substances widely distributed in herb and spices act mostly as radical scavengers and some are act as metal chelators. Therefore, these compounds have been considered as promising candidates as potential protectors against lipid oxidation. The presence of an antioxidant is one of the fastest ways to reduce fat oxidation (Abdullahi, 2011). Mostly antioxidant acts as hydrogen donors to the lipid free radical formed during the lipid oxidation and rearrange to a stable conformation (Gad and Sayd, 2015).

\section{Methods for measuring the antioxidant activity}

Antioxidant activity can be monitored by a variety of assays such as DPPH (2,2diphenyl-1 picrylhydrazyl radical, ABTS [2,2-azinobis-(3-ethylbenzothiazoline-6sulphonate) radical cation] or Trolox equivalent antioxidant capacity (TEAC), FRAP (ferric reducing antioxidant power) and ORAC(oxygen radical absorbance capacity). Total phenolic content (TPC) is another important parameter of total antioxidant capacity (TAC), and widely used for evaluation of antioxidant extracts, including extracts from herbs and spices. The Folin- Ciocalteu assay is the wellknown method for determination of TPC. Decomposition of the unstable peroxides derived from polyunsaturated fatty acids results in the formation of malondialdehyde (MDA), which can be quantified using TBARS assay (Boligon et al., 2014; Ali et al., 2008).

\section{Applications}

Applications of both extracts and essential oil (EO) of herbs and spices have been reported in oil, dairy products, bakery products, meat products, fish products, edible film and packaging film.

\section{Oils}

The antioxidant activity of dichloromethane extract from ginger was evaluated during 6 months of storage of refined sunflower oil at 25 and $45^{\circ} \mathrm{C}$. Free fatty acid content, peroxide value and iodine value were used as criteria to assess ginger extract as an antioxidant at various concentrations (800ppm, 1600 and 2400ppm). The autoxidation of sunflower oil was greatly inhibited in the presence of ginger extract at concentrations of 1600 and 2400ppm. There was no significant difference $(\mathrm{P}<0.05)$ between synthetic antioxidants (200ppm) and ginger extract (1600 and 2400ppm) in the inhibition of sunflower oil peroxidation. It is also obvious from these results that iodine values of sunflower oil treated with ginger extract (2400ppm) and 200ppm of synthetic antioxidants (BHA, BHT) were almost equal after 6 months of storage at 25 and $45^{\circ} \mathrm{C}$. The results illustrated that ginger extract at concentrations (1600 and 2400ppm) exhibited very strong antioxidant activity, almost equal to that of synthetic antioxidant (BHA at 200ppm). Therefore the use of ginger extract in foods is recommended as a natural antioxidant to suppress lipid oxidation (Zia-ur-Rehman et al., 2003).

Ginger extract was also heated at $185^{\circ} \mathrm{C}$ for various times $(0,20,30,40,60,90$ and $120 \mathrm{~min})$. The result of heat treatment illustrated that ginger extract exhibited $85.2 \%$ inhibition of peroxidation of linoleic acid on heating at $185^{\circ} \mathrm{C}$ for $120 \mathrm{~min}$. Therefore ginger extract showed good thermal stability in comparison with BHA. Thermal stability testing of ginger extract during frying of sunflower oil was also 
performed. For this purpose, fresh sunflower oil containing $2400 \mathrm{ppm}$ ginger extract was heated at frying temperature $\left(185^{\circ} \mathrm{C}\right)$ for 50h. During the frying process, oxidation, hydrolysis, polymerisation and other chemical reactions occur, leading to the deterioration of fats and oils. It is well known that these reactions ultimately adversely affect the free fatty acid content, peroxide value and iodine value of sunflower oil during heating. Therefore free fatty acid contents, peroxide values and iodine values were used to assess the thermal stability of ginger extract. There is unnoticeable change was found in free fatty acid contents, peroxide values and iodine values during frying. The chemical characteristics remained almost unchanged when sunflower oil containing 2400ppm ginger extract was heated at $185^{\circ} \mathrm{C}$ for $50 \mathrm{~h}$. These results that ginger extract is thermally stable, as the chemical characteristics of sunflower oil did not change much in the presence of ginger extract during prolonged heating, and therefore may be used in the frying or thermal processing of foods (Ziaur-Rehman et al., 2003).

Delre and Jorge (2010) used oregano (Oreganum vulgare L.), basil (Ocimum basilicum L.) and thyme (Thymus vulgaris L.) oleoresins in soybean oil. Different concentrations of oleoresins (500, 1000, 1500, 2000, 2500, and $3000 \mathrm{mgkg}^{-1}$ ) were added. At $3000 \mathrm{mgkg}^{-1}$ of thyme and oregano oleoresins had greatest oxidative stability

Fasoyiro et al. (2001) used Aframomum danelli spice in Palm and soybean oil. The activity of $A$. danielli extract was compared with rosemary and sage extract at different concentrations. At 200ppm and 300ppm , Palm and soybean oil reduced the rate of peroxide formation.

Ozcan (2003) used rosemary, sage, and sumac extracts and their combinations in peanut oil. Methanolic extracts were applied (at 4\%) (wt/vol, extract/oil) to peanut oil stored at $80^{\circ} \mathrm{C}$ for $24 \mathrm{~h}$. The most effective ones were sage + sumac (peroxide value). Therefore, Sumac extract is recommended as a source of natural antioxidant.

\section{Dairy products}

Different levels of ginger (Zingiber officinale) extract and beet root (Beta vulgaris) extract were used to produce the herbal yoghurt from cow, buffalo and goat milks and analysed for their antioxidant activity. The result indicated that highest antioxidant activities with DPPH \& FRAP methods were found in $2 \%$ level of ginger in goat milk yoghurt and $2 \%$ level of beet root extracts in goat milk yoghurt followed by $2 \%$ level of ginger extract in cow milk yoghurt. The lowest antioxidant activity was found in buffalo milk herbal yoghurt (Srivastava et al., 2015).

Bandyopadhyay et al. (2007) used beet (Beta vulgaris), mint (Mentha spicata L.) and ginger (Zingiber officinale L.) alone or in combination in sandesh and also assessed after their fortification in sandesh for their antioxidant activities. Among the natural sources, ginger and combination of ginger with mint represented excellent results. Use of BHA and BHT can be substituted by natural sources (beet, mint, ginger) alone or in combined form.

Singh and Immanuel (2014) used peels of pomegranate, lemon and orange as sources of natural antioxidants in paneer. The ability to prevent peroxide formation in paneer sample was in the order of pomegranate peel> lemon peel> orange peel.

Sivakumar et al. (2014) assessed the effect of betel leaves (Piper betel L.) extract on the antioxidant properties of khoa made from cow's milk which was stored at room 
temperature. Khoa with $0.5 \%$ aqueous extract of betel leaves restricted the production of free fatty acid compared to control due to antioxidant property of betel leaves.

Parmar et al. (2013) reported that ethanolic extract of Arjuna bark increased the shelf life of ghee as compared to control sample during storage at $8^{\circ} \mathrm{C}$. Their findings also suggested that freshly prepared ghee from cow milk added with Arjuna bark had good potentiality to act as free radical scavenger.

The juice of amla fruit (Emblica officinalis) has marked antioxidant property when added at the rate of $1.25 \%$ in ghee. It retards the onset of rancidity to the same extent as did $0.1 \%$ propyl gallate and $0.01 \%$ citric acid. The antioxidant property of amla juice was attributed to its high ascorbic acid and gallates content (Ahmad et al., 1960).

Gandhi et al. (2013) evaluated antioxidative properties of Viadarikand ethanolic extract in ghee and reported that ethanolic extract of the vidarikand was more effective for preventing the development of the peroxide value and conjugated diene value in ghee during storage. Vidarikand ethanolic extract showed the higher induction period as compare to control ghee sample.

Patel et al. (2013) assessed the antioxidant activity of coriander extract in ghee and reported that coriander extract added ghee gave better oxidative stability of ghee during storage as compare to control sample but they also suggested that for ghee BHA is more effective antioxidant than coriander extract.

\section{Bakery products}

Clove essential oil (CEO) was evaluated for its antioxidant effect in cakes by determining the peroxide value, thiobarbitoric acid and free fatty acid content during 28 days of storage at room temperature. The results showed that the CEO was able to retard the oxidation rate and reduction of formed oxidation products in cakes compared with synthetic antioxidant (Ibrahium et al., 2013).

Hinar et al. (2014) determined the effect of adding some aromatic and medicinal plants (garlic, coriander, sumac, fennel, marjoram, thyme and cardamom) as natural antioxidants in bread. All bread samples exhibited higher antioxidant activity than control.

Darughe et al. (2012) used coriander essential oil (CEO) as sources of natural antioxidants in cake. Antioxidant activities of CEO were evaluated in cake during 60 days storage at room temperature. The results indicated that, $\mathrm{CEO}$ at $0.05,0.10$ and $0.15 \%$ inhibited the rate of oxidation products formation in cake and their effects were almost equal to BHA at $0.02 \%$.

\section{Meat products}

In a study by Singh et al. (2014) raw chicken meat emulsion was incorporated with clove powder, ginger and garlic paste. Four different batches of chicken meat emulsion i.e. $\mathrm{C}=$ Control (without natural preservatives), $\mathrm{T}_{1}=0.2 \%$ clove powder, $\mathrm{T}_{2}$ $=3 \%$ ginger paste and $\mathrm{T}_{3}=2 \%$ garlic paste, were analyzed for its shelf life evaluation during refrigerated storage $\left(4 \pm 1^{\circ} \mathrm{C}\right)$ of 9 days under aerobic packaging. $0.2 \%$ clove powder maintained lowest TBA value till the end of storage. DPPH and ABTS radical scavenging activity was significantly higher $(\mathrm{P}<0.05)$ in $\mathrm{T}_{1}$ batch as compared to control. From this comparative study of natural preservatives, it was concluded that $0.2 \%$ clove powder could be utilized effectively as antioxidant in raw chicken meat emulsion. 
Other application in meat products was reported by Baker et al. (2013). They prepared lamb patties from minced meat. Treatment 1 was considered as a control; treatments 2 and 3 were blended with $0.05 \%$ rosemary extract (RE), and $0.50 \%$ ginger (GE), respectively. Whereas treatments 4 and 5 were blended with $3 \%$ sodium lactates in addition to rosemary (RE+ SL) or ginger $(\mathrm{GE}+\mathrm{SL})$. All treated lamb patties significantly retarded oxidative process compared to control patties.

\section{Fish products}

Normah et al. (2005) determined the potential effects of ginger and coriander on reducing lipid oxidation of cooked patties of Mackerel during refrigerated storage. Four treatments were used consisting of fish + coriander $(1 \%)$, fish + ginger $(1 \%)$, fish + ginger $(0.5 \%)+$ coriander $(0.5 \%)$ and fish only as a control. Lipid oxidation was evaluated based on the peroxide value and free fatty acid value. Sensory evaluation of samples was carried out to judge rancid odor. From this study, antioxidant activity increased in the order of coriander $<$ ginger + coriander $<$ ginger. From the observation for 12 days of refrigerated storage $\left(4{ }^{\circ} \mathrm{C}\right)$, it was found that rancidity increased with storage period. The degree of rancid odor increased in the order of coriander $>$ ginger + coriander $>$ ginger.

Zarina and Tan (2013) determined flavonoids in Citrus grandis (Pomelo) peels and their inhibition activity on lipid oxidation in fish tissue. They evaluated flavonoid activity towards lipid oxidation in the fish tissue and found reduction in peroxide value which indicated the inhibition of lipid oxidation in fish treated with pomelo peel.

\section{Edible film}

Edible film was prepared by incorporation of ginger essential oil in uwi starch (Dioscorea alata L). DPPH scavenging assay was used to indicate antioxidant activity of the film. As the concentration of essential oil was increased, DPPH scavenging activity of the films increased significantly. The best antioxidant occurs in $3 \%$ essential oil with $31.5 \%$ reduction of DPPH (Herlina and Masril, 2013).

\section{Packaging film}

Protective effects of plant extracts incorporated in cellulose-based pouches in stabilizing soybean oil were tested by measuring their peroxide values and free fatty acid contents during accelerated storage.

Soybean oil samples packed with antioxidant-free cellulose-based pouches (control) reached a maximum peroxide value of $558 \mathrm{meqkg}^{-1}$ after 8 weeks of storage. The peroxide value of soybean oil samples packed with cellulose-based pouches containing BHA, cinnamon oil and clove oil were 517,484 and 530 meqkg$^{-1}$ respectively, after 8 weeks under accelerated storage conditions. The corresponding inhibition rates were $7.2 \%, 13.3 \%$ and $4.8 \%$ respectively, compared with the control. Furthermore, the antioxidant effect of cinnamon oil was superior to BHA. Soybean oil samples packed in antioxidant-free cellulose-based pouches (control) reached a maximum FFA level of $1.37 \mathrm{mg} \mathrm{KOH} \mathrm{g}^{-1}$ after 8 weeks of storage. The FFA of soybean oil samples packed with cellulosebased pouches containing BHA, cinnamon oil and clove oil were 1.42, 1.38 and 1.23 $\mathrm{mg} \mathrm{KOH} \mathrm{g}{ }^{-1}$, respectively. After 8 weeks under accelerated storage conditions, the antioxidant effects of clove oil yielded inhibition rate of $10.6 \%$. This study showed the potential use of plant extracts (cinnamon and clove oil) as antioxidants for food 
packaging application (Phoopuritham et al., 2012).

\section{Advantages and Limitations}

One of the challenges in using spices and herbs as food antioxidants is their strong flavor and aroma. Some suppliers deodorize the extracts to some extent so that they can be used without affecting the sensory properties of the food product. It has been reported that whole spices have greater activity than their extracts or isolated components. Therefore minor components are critical to the activity due to their synergistic effect or potentiating influence on activity of the minor components (Shahidi, 2015).

\section{Regulatory Status}

Some herb and spice extracts and oleoresins are Generally Recognized as Safe (GRAS). Some are considered to be indirect additives as such, solvents permitted for the extraction process and solvent residues allowed are specified. Some extracts, concentrates, and resins are regulated by the FDA "Dietary Supplement Health and Education Act of 1994" and are considered as dietary ingredients for use to supplement the diet by increasing the total dietary intake.

Extracts, concentrates, and resins are also regulated under the Food Labeling Regulation, Amendments; Food Regulation Uniform Compliance Date; and New Dietary Ingredient Premarket Notification Final Rule (1997). Based on the number of various classifications under which an extract, concentrate or resin could be covered, allowable use levels vary widely (Brewer, 2011).

According to FSSAI regulations spices may be used in milk ice, frozen dessert, ice cream, cream cheese, cottage cheese, processed cheese and cheese spread, shrikhand, bread, ready-to-Eat vegetables, frozen vegetables, frozen fruits/fruit products, soyabean sauce, culinary pastes /fruits and vegetable sauces, tomato ketchup and tomato sauce, vegetable juices and soups, pickles, synthetic vinegar, mango chutney, pasta products, fruits and vegetable chutney and meat products (canned chopped meat, canned cooked ham) (FSSAI, 2011). However, upper limit of their application is not specified.

In conclusion, extracts from spices and herbs are classified as natural and thus are in great demand. These extracts will continue to play a very important role in food preservation and more research will be undertaken in various areas to improve utilization of spices and herbs as antioxidants and to increase their availability and efficacy. (1) refine extraction and isolation methods, (2) optimize extraction processes, (3) optimize the synergistic effect of combining natural antioxidants, (4) isolate and identify key compounds from spices and herbs responsible for antioxidant activity (5) development of novel processes to reduce aroma and flavor in the extracts.

\section{References}

Abdullahi, M. 2011. Biopotency role of culinary spices and herbs and their chemical constituents in health and commonly used spices in Nigerian dishes and snacks. African J. Food Sci., 5(3): 111-124.

Ahmad, I., Karimullah, M.K.N., Saeed, M.K. 1960. A comparative study of amlaproducts and synthetic antioxidant for edible fats. Pakistan J. Sci. Res., 12: 71.

Ali, S.S., Kasoju, N., Luthra, A., Singh, A., Sharanabasava, H., Sahu, A., Bora, U. 2008. Indian medicinal herbs as sources of antioxidants. Food Res. Int., 
41: 1-15.

Baker, I.A., Alkass, J.E., Saleh, H.H. 2013. Reduction of Oxidative Rancidity and Microbial Activities of the Karadi Lamb Patties in Freezing Storage Using Natural Antioxidant Extracts of Rosemary and Ginger. Int. J. Agri. Food Res., 2: 31-42.

Bandyopadhyay, M., Chakraborty, R., Raychaudhuri, U. 2007. A process for preparing a natural antioxidant enriched dairy product (Sandesh). Lebensmittel-Wissenschaft UndTechnologie, 40: 842-851.

Boligon, A.A., Machado, M.M., Athayde, M.L. 2014. Technical Evaluation of Antioxidant Activity. Med. chem., 4: 517-522.

Brewer, M.S. 2011. Natural Antioxidants: Sources, Compounds, Mechanisms of Action, and Potential Applications. Comprehensive Reviews in Food Science and Food Safety, 10: 221-247.

Carlsen, M.H., Halvorsen, B.L., Holtel, K., Bohn, S.K., Dragland, S., Sampson, L. 2010. The total antioxidant content of more than 3100 foods, beverages, spices, herbs and supplements used worldwide. Nutr. J., 9: 3-14.

Darughe, F., Barzegar, M., Sahari, M.A. 2012. Antioxidant and antifungal activity of Coriander (Coriandrum sativum L.) essential oil in cake. Int. Food Res. J., 19: 1253-1260.

Delre, P.V., Jorge, N. 2010. Antioxidant potential of oregano (Oreganum vulgare L.), basil (Ocimum basilicum L.) and thyme (Thymus vulgaris L.): application of oleoresins in vegetable oil. Ciência e Tecnologia de Alimentos, 31: 955-959.

Fasoyiro, S.B., Adegoke, G.O., Obatolu, V.A., Ashaye, O., Aroyeun, S.O. 2001. The antioxidant property of Aframomum danelli spice in oils. $J$. Food Technolo. Africa, 6: 135-137.
Frankel, E.N. 2012. Antioxidants in food and biology- Facts and fiction. Woodhead Publishing in Food Science, Technology and Nutrition. University of California, California, USA. pp: 25-33.

FSSAI 2011. Food product standard and food additives. Ministry of health and family welfare, New Delhi. pp. 210211.

Gad, A.S., Sayd, A.F. 2015. Antioxidant Properties of Rosemary and Its Potential Uses as Natural Antioxidant in Dairy Products - A Review. Food Nutr. Sci., 6: 179-193.

Gandhi, K., Arora, S., Nilkanth, P., Kumar, A. 2013. Effect of Vidarikand (extracts) on oxidative stability of ghee: A comparative study. Research and Reviews: J. Dairy Sci. Techno., 2: 1.

Herlina, M., Masril, K. I. (2013). Antibacterial and Antioxidant of Uwi (Dioscorea Alata L) Starch Edible Film Incorporated with Ginger Essential Oil. Int. J. Biosci., Biochem. and Bioinform., 3: 354-356.

Hinar A. Seleem., Zahrat El-Ola M. Mohamed. 2014. Influence of Some Medicinal and Aromatic Plants Addition on Pan Bread Quality. World J. Dairy and Food Sci., 9: 299-307.

Ibrahium, M.I., Abd El-Ghany, M.E., Ammar, M.S. 2013. Effect of Clove Essential Oil as Antioxidant and Antimicrobial Agent on Cake Shelf Life. World J. Dairy and Food Sci., 8: 140-146.

Kaefer, C.M., Milner, J.A. 2008. The role of herbs and spices in cancer prevention. J Nutr. Biochem., 19: 347-361.

Normah, I., Diana, W., Norisuliana, I., Azura, A. 2005. Antioxidative activity of ginger and coriander in cooked patties of mackerel. Sci. Letters, 2: 7177. 
Ozcan, M. 2003. Antioxidant Activities of Rosemary, Sage, and Sumac Extracts and Their Combinations on Stability of Natural Peanut Oil. J. Med. Food, 6: 267-270.

Parmar, P., Kaushik, K., Devaraja, H.C., Singh, R.R.B. 2013. The effects of alcoholic extract of Arjuna (Terminalia arjuna.) bark on stability of clarified butterfat. J. Med. Plants Res., 7: 2245-2252.

Patel, S., Shende, S., Arora, S., Singh, A.K. 2013. An assessment of the antioxidant potential of coriander extracts in ghee when stored at high temperature and during deep fat frying. Int. J. Dairy Techno., 66: 207.

Peter, K.V. 2001. Handbook of herbs and spices - volume 1. Woodhead Publishing Limited. Cambridge, England. pp: 14-21.

Phoopuritham, P., Thongngam, M., Yoksan, R., Suppakul, P. 2012. Antioxidant Properties of Selected Plant Extracts and Application in Packaging as Antioxidant Cellulose-Based Films for Vegetable Oil. Packag. Technol. Sci., 25: 125-136.

Pokorny, J., Yanishlieva, N., Gordon, M. 2001. Antioxidants in food-Practical applications. Woodhead Publishing Limited, Cambridge, England. pp: 134.

Sati, Y.A. Al-Dalain, A.H., Al-Fraihat, E.T. 2011. Effect of Aromatic Plant Essential Oils on Oxidative Stability of Sunflower Oil During Heating and Storage. Pakistan J. Nutr., 10: 864870.
Shahidi, F. 2015. Handbook of Antioxidants for Food Preservation. Woodhead Publishing Series in Food Science, Technology and Nutrition, UK. pp: 251-285.

Singh, P., Sahoo, J., Chatli, M.K., Biswas, A.K. 2014. Shelf life evaluation of raw chicken meat emulsion incorporated with clove powder, ginger and garlic paste as natural preservatives at refrigerated storage $\left(4 \pm 1^{\circ} \mathrm{C}\right)$. Int. Food Res. J., 21: 1363-1373.

Singh, S., Immanuel, G. 2014. Extraction of Antioxidants from Fruit Peels and its Utilization in Paneer. J. Food Process Technol., 5: 349-354.

Sivakumar, G.M., Dhanalakshmi, B., Nareshkumar, C., Pugazhenthi, T.R. 2014. Antioxidant activity of herbal extract on khoa. Ind. J. Vet. And Anim. Sci. Res., 43: 445-451.

Srivastava, P., Prasad, S.G.M., Mohd Nayeem Ali., Prasad, M. 2015. Analysis of antioxidant activity of herbal yoghurt prepared from different milk. Pharma Inno. J., 4: 18-20.

Suhaj, M. 2006. Spice antioxidants isolation and their antiradical activity: a review. J. Food Compo. and Anal., 19: 531537.

Zarina, Z., Tan, S.Y. 2013. Determination of flavonoids in Citrus grandis (Pomelo) peels and their inhibition activity on lipid peroxidation in fish tissue. Int. Food Res. J., 20: 313-317.

Zia-ur-Rehman, Salariya, A.M., Habib, F. 2003. Antioxidant activity of ginger extract in sunflower oil. J. Sci. Food and Agri., 83: 624-629.

\section{How to cite this article:}

Dhartiben B. Kapadiya, Bhumika K. Dabhi and Kishorkumar D. Aparnathi. 2016. Spices and Herbs as a Source of Natural Antioxidants for Food. Int.J.Curr.Microbiol.App.Sci. 5(7): 280288. doi: $\underline{\text { http://dx.doi.org/10.20546/ijcmas.2016.507.029 }}$ 